Los programas locales de salud pueden contribuir a reducir la mortalidad infantil

Hasta el momento no se había demostrado que los sistemas locales de salud pudieran reducir la mortalidad infantil en las poblaciones a las que atienden. La mayoría de los estudios vinculados con este tema se han realizado en poblaciones pequeñas y en muchos de ellos faltó un grupo de comparación o no se logró demostrar que la reducción de la mortalidad se debiera a las intervenciones realizadas.

En este artículo se compara la mortalidad de niños menores de 5 años que vivían en el área de atención primaria del Hospital Albert Schweitzer (HAS), ubicado en Deschapelles, Haití, con el promedio nacional. El HAS cuenta con un sistema integrado de atención sanitaria que abarca servicios primarios de salud basados en la comunidad, atención hospitalaria y desarrollo comunitario. Se entrevistó a $10 \%$ de las mujeres en edad reproductiva que residían en el área atendida por el HAS y se documentaron 2390 nacimientos y 149 muertes infantiles en el período entre 1995 y 1999.

En comparación con todo el país, en el área atendida por el HAS la mortalidad en menores de 5 años fue $58 \%$ más baja y la de niños de 12 a 59 meses de edad, $76 \%$ menor. Estos resultados se lograron a pesar de contar con menos médicos y camas hospitalarias por habitante en comparación con las cifras nacionales, pero con el doble de enfermeros graduados y auxiliares por habitante. Además se contó con tres categorías de trabajadores sanitarios que no existen en el resto de Haití: ayudantes médicos, agentes sanitarios y voluntarios de salud comunitaria. La cobertura de los servicios dirigidos a proteger la vida de los menores fue por lo general de 1,5 a 2,0 veces mayor en el área atendida por el HAS que en el resto de las zonas rurales de Haití.

Las principales causas de mortalidad infantil en el área atendida por el HAS son prevenibles o curables. La desnutrición, la neumonía y la diarrea causan $47 \%$ de las muertes, mientras que el tétanos y el sarampión - ambas enfermedades prevenibles mediante vacunas- ocasionan $5 \%$ de las muertes en recién nacidos. Además, $12 \%$ de las muertes de los neonatos se deben a los partos prematuros y a otras complicaciones obstétricas. Se calcula que aproximadamente $20 \%$ de las muertes de niños menores de 5 años en el área atendida por el HAS están relacionadas con la infección por el virus de la inmunodeficiencia adquirida y el sida.

El riesgo de morir antes de cumplir 5 años de edad de los niños que residen en el área de atención del HAS es menos de la mitad del que tienen los niños del resto del país.
Estos resultados respaldan la hipótesis de que con un sistema integrado de atención primaria de salud basado en la comunidad y de fácil acceso que disponga de un hospital de referencia y que lleve a cabo actividades básicas de desarrollo comunitario se puede reducir a la mitad la mortalidad de niños de 0 a 59 meses de edad en zonas de extrema pobreza y subdesarrollo. Los resultados indican que los programas de salud del HAS fueron la causa de esa diferencia, lo que respalda la idea de que el reforzamiento de los programas locales de salud y la promoción del desarrollo comunitario pueden contribuir a reducir la mortalidad infantil.

El establecimiento de sistemas locales de salud y de desarrollo en zonas de extrema pobreza puede desempeñar un papel importante en la consecución del objetivo de desarrollo del milenio de reducir en dos tercios la mortalidad infantil antes del año 2015. (Perry H, et al. Reducing under-five mortality through Hospital Albert Schweitzer's integrated system in Haiti. Health Policy Plan. 2006; 21:217-30.)

\section{La transmisión de la cardiopatía coronaria por los padres}

El tener padre o madre con cardiopatía coronaria (CPC) constituye un factor de riego de sufrir esa enfermedad. En este artículo se presentan los resultados de un estudio prospectivo de todos los casos de ingreso hospitalario por CPC entre suecos nacidos de 1932 en adelante y sus padres (alrededor de 11 millones de personas). Los datos se tomaron del Registro Multigeneracional de Suecia.

El objetivo fue comparar la transmisión materna o paterna de la CPC a hombres y mujeres, ajustada por el sexo, la edad en el momento del diagnóstico, los antecedentes materno y paterno de CPC, el estado laboral y la región de Suecia en que vivía el paciente. El registro de los casos de CPC de los pacientes y de sus padres (dos generaciones) abarcó del 1 de enero de 1987 hasta el 31 de diciembre de 2001. Algunos casos contabilizados de CPC en los padres pueden haber sido readmisiones, mientras que los pacientes índices tuvieron primeros episodios solamente. En total, se obtuvo información de 98,5 millones de años-hombre y de 94,2 millones de años-mujer. Se excluyó solamente a $0,8 \%$ de las personas, debido a la falta de algún dato. Los casos de CPC anteriores a 1997 se clasificaron según la 9. ${ }^{a}$ edición de la Clasificación internacional de enfermedades (CIE-9; códigos 410-414) y los casos posteriores se clasificaron según la $10 .^{a}$ edición (CIE-10; códigos I20-I25). Se calculó la razón de incidencia estandarizada (RIE) con sus intervalos de confianza de 95\% (IC95\%); se empleó como 